\title{
Should Monetary Policy Respond to Asset Price Misalignments?
}

\author{
Alexandros Kontonikas * \\ and Christos Ioannidis
}

Department of Economics and Finance, Brunel University, Uxbridge, UK

\begin{abstract}
This paper analyses the relationship between monetary policy and asset prices using a structural rational expectations model that allows for the effect of asset prices on aggregate demand. We assume that asset prices follow a partial adjustment mechanism whereas they are positively affected by past changes, thus allowing for 'momentum trading', while at the same time we allow for reversion towards fundamentals. We then conduct stochastic simulations using two alternative monetary policy rules, inflation-forecast targeting and the standard Taylor rule. The results indicate that, under both rules, interest rate setting that takes into account asset price misalignments leads to lower overall macroeconomic volatility, as measured by the postulated loss function of the central bank.
\end{abstract}

JEL classifications: E44; E52; E60

Keywords: Monetary policy; Asset prices

* Corresponding author. Tel.: +44-1895-203352; fax: +44-1895-203384.

E-mail address: alexandros.kontonikas@brunel.ac.uk

We would like to thank Professor Charles Goodhart for his most valuable comments and suggestions on an earlier version of the paper. 


\section{Introduction}

The exuberant bull stock market associated with the 'new economy' and the 'dot com' boom of the 1990s came into an abrupt halt in early 2000. Since then, stock price indices have fallen and are far bellow the levels they reached in the late 1990s. Economic history provides plenty examples of asset price bubbles beginning as early as the seventeenth century ${ }^{1}$. Apart from the 'internet bubble', the previous century witnessed two other major episodes of sudden asset price reversals after long periods of sustained rises: the 1929 US stock market crash and the Japanese experience of the late 1980s and early 1990s. Both episodes exhibited a regular characteristic of asset price boom-bust cycles, that is, the decline in asset prices was followed by a slowdown in economic activity as well as increased financial and banking sectors instability. Recent work by Detken and Smets (2003) on a large sample of industrial countries indicates that the boom phase typically features rising money, output and credit gaps, and low interest rates relative to a Taylor rule benchmark. It has been argued that the widespread financial deregulation of asset markets that began in the1980s may have contributed to an increase in the frequency of such episodes (IMF, 2003).

As Bordo and Jeanne (2002) point out, during the boom period the domestic private sector accumulates high levels of debt on the expectation of further rises in asset prices, whilst the assets themselves serve as a collateral. When asset prices fall, the decline in the value of the collateral induces consumers to cut back expenditure and firms to reduce investment spending. In essence, the deterioration of balance sheets, following large asset price reductions, further exacerbates the negative 'wealth effect' on spending, leading to additional negative effects on asset prices, bank lending and economic output (collateral-induced credit crunch). In a number of articles, Charles Goodhart and Boris Hofmann establish empirically the link between output growth, credit aggregates, and asset price movements in a number of major economies ${ }^{2}$. A recent study by the IMF (2003) analyses the after-effects of sharp asset price reversals and finds that equity prices reductions are quite frequent and are associated with heavy GDP losses. In addition, Borio and Lowe (2002) stress that swings in asset prices have historically accompanied episodes

\footnotetext{
${ }^{1}$ See Garber (2000) for a discussion on the tulip mania in the early seventeenth century as well as other famous bubbles.

${ }^{2}$ See Goodhart and Hofmann (2000, 2001, 2003). See also Kiyotaki and Moore (1997), for a theoretical model that exhibits a crucial interaction between collateral values, asset prices, credit and economic activity. Kocherlakota (2000) shows that in the presence of credit constraints which depend upon the collateral value, shocks to income may be amplified and produce asymmetric effects in that, negative shocks have larger effects than positive ones.
} 
of financial instability. In particular, there is concern that asset price boom and busts could create systemic financial risk ${ }^{3}$.

An important issue related to the above concerns is the establishment of the appropriate monetary policy response to asset price fluctuations. Should the central bank care about financial instability? Nowadays, everyone recognizes price level stability as the primary objective of monetary policy. Indeed, as Issing (2003) emphasizes, price stability and financial stability tend to mutually reinforce each other in the long run. However, as the examples of the US in the 1920s and 1990s and Japan in the late 1980s demonstrate, financial imbalances may build up even in an environment of stable prices (Borio and Lowe, 2002). Exponents of the 'new environment' hypothesis argue that low and stable rates of inflation may even foster asset price bubbles, due e.g. to excessively optimistic expectations about future economic development. Thus, price stability is not a sufficient condition for financial stability. If, in fact, financial stability is defined narrowly, as the degree of interest rate smoothness in the economy, and not widely, as the prevalence of a financial system that continuously ensures the efficient allocation of savings to investment opportunities, then a trade-off between monetary (or price) stability and financial stability may arise ${ }^{4}$.

The monetary policy response to asset price developments can take two forms, either proactive, or reactive. A reactive approach is consistent with an inflation targeting policy regime focusing on price stability and according to it, the monetary authorities should wait and see whether the asset price reversal occurs, and if it does, to react accordingly to the extent that there are implications for inflation and output stability. Hence, the reactive approach is consistent with an accomodative ex post response to asset price changes. Bernanke and Gertler $(1999,2001)$ simulate alternative variants of the Taylor rule in the context of the new keynesian model with sticky wages and a financial accelerator and find that a central bank dedicated to price stability should pay no attention to asset prices per se, except insofar as they signal changes to expected inflation. They also argue that trying to stabilise asset prices is problematic since it is nearly impossible to know for sure whether a given change in asset values results from fundamental factors, non-fundamental factors, or both. Gilchrist and Leahy (2002) employ three alternative

\footnotetext{
${ }^{3}$ We should mention, however, that the empirical evidence linking asset price reversals with banking crises is rather limited and inconclusive. See, among others, the paper by Vila (2000).

${ }^{4}$ For instance, in the presence aggregate demand shocks, the trade-off derives from the fact that the central bank would have to decide to which degree it prefers interest rate stabilisation over inflation and output stabilisation.
} 
dynamic general equilibrium models and, in agreement with Bernanke and Gertler, reach the conclusion that asset prices should not be included in the monetary policy rule.

Against this, Cecchetti, Genberg, Lipsky and Wadhwani (2000), using the same theoretical model as Bernake and Gertler (1999), claim that "a central bank concerned with both hitting an inflation target at a given time horizon, and achieving as smooth a path as possible for inflation, is likely to achieve superior performance by adjusting its policy instruments not only to inflation (or to its inflation forecast) and the output gap, but to asset prices as well" (p.2). Ceccheti et al argue that such a proactive response will reduce the likelihood of asset price bubbles forming, thus reducing the risk of boom-bust investment cycles. Bernanke and Gertler (2001) attribute their findings to, among other factors, the use of a misleading metric in the comparison between policy rules.

In this paper we take another look at the interaction between monetary policy and asset prices using a small rational expectations model that takes into account the effect of asset prices on aggregate demand in order to capture investment and consumption wealth effects. Using stochastic simulations, we then examine how inflation, output, interest rates, and asset prices behave under alternative policy rules. Our results confirm previous findings by Cecchetti et al (2000) in that, macroeconomic volatility can be reduced with a mild reaction of interest rates to asset price misalignments from fundamentals. Our main contribution lies in the fact that in our simulations we employ two alternative monetary policy rules, inflation forecast targeting, and the standard Taylor rule, with the main conclusions for the role of monetary policy with respect to asset prices remaining unchanged. We also incorporate an alternative partial adjustment mechanism of asset prices towards their fundamental value that allows for both 'momentum trading' and 'fundamentals pull'.

The remainder of the paper is structured as follows. The next section describes the theoretical model that will be employed in the simulations. In Section 3 we calibrate the model's structural parameters on the basis of previous econometric evidence for the UK economy. Section 4.1 presents the results from impulse response analysis, and Section 4.2 compares the effect on macroeconomic uncertainty from alternative monetary policy choices. Section 5 provides conclusions. 


\section{Model}

We use a structural model of the economy that allows for the effect of asset prices on aggregate demand and monetary policy. The model augments the standard three sector macro model (aggregate demand, aggregate supply, monetary policy rule) by taking into account asset prices, which themselves are assumed to stochastically evolve influenced by both fundamentals and momentum. The model is given by the following equations:

$$
\begin{aligned}
& y_{t}=E_{t}\left[y_{t+1}\right]-a_{1}\left(i_{t-1}-E_{t-1}\left[\pi_{t}\right]\right)+a_{2} q_{t-1}+\eta_{t} \\
& \pi_{t}=(1-\varphi) E_{t}\left[\pi_{t+1}\right]+\varphi \pi_{t-1}+\beta\left(y_{t}-\bar{y}_{t}\right)+\varepsilon_{t} \\
& q_{t}=b_{1} \Delta q_{t-1}-b_{2}\left(q_{t-1}-q_{t}^{*}\right) \\
& q_{t}^{*}=-\delta_{1}\left(i_{t}-E_{t}\left[\pi_{t+1}\right]\right)+\delta_{2} E_{t}\left[y_{t+1}\right]+u_{t} \\
& i_{t}=\left(1-\gamma_{4}\right)\left[r+\pi_{t}+\gamma_{1}\left(\pi_{t}-\pi^{*}\right)+\gamma_{2}\left(y_{t}-\bar{y}_{t}\right)+\gamma_{3}\left(q_{t}-q_{t}^{*}\right)\right]+\gamma_{4} i_{t-1}+\theta_{t} \\
& i_{t}=\left(1-\gamma_{4}\right)\left[r+\gamma_{1}^{*}\left(E_{t}\left[\pi_{t+j}\right]-\pi^{*}\right)+\gamma_{3}\left(q_{t}-q_{t}^{*}\right)\right]+\gamma_{4} i_{t-1}+\theta_{t}
\end{aligned}
$$

where $y_{t}$ is $(\log )$ output, $\bar{y}_{t}$ is the natural-rate value of $y_{t}, \tilde{y}_{t}=y_{t}-\bar{y}_{t}$ is the output gap, $\pi_{t}=p_{t}-p_{t-1}$ is the inflation rate, $p_{t}$ is (log) price level, $i_{t}$ is the monetary policy instrument (oneperiod nominal interest rate, e.g. repo rate, $r$ is the equilibrium real interest rate and $\pi^{*}$ is the inflation target. $q_{t}$ denotes $(\log )$ real asset prices and $q_{t}{ }^{*}$ the fundamentals. Different interpretations of $q_{t}$ are possible (e.g. house prices, stock prices or the value of a portfolio containing both housing and equity investment), in what follows though we mainly treat it is an equity index. $\eta_{t}, \varepsilon_{t}, \theta_{t}, u_{t}$ represent exogenous random shocks to output, inflation, nominal interest rates and asset price fundamentals. Their innovations are mutually uncorrelated i.i.d. processes with zero means and constant variances: ${\sigma_{\eta}}^{2}, \sigma_{\theta}{ }^{2}, \sigma_{\varepsilon}{ }^{2}, \sigma_{u}{ }^{2}$. The natural-rate output, $\bar{y}_{t}$, is $\operatorname{AR}(1)$ process; its innovation, $\omega_{t}$, has constant variance $\sigma_{\omega}{ }^{2}$. The structural parameters can be interpreted as partial elasticities with the following properties: $a_{1}, \beta, \gamma_{1}, \gamma_{2}, \delta_{1}, \delta_{2}, b_{1}, b_{2}>0$, $a_{2}, \gamma_{3} \geq 0, \varphi>0, \gamma_{4}<1$.

Eq. (1) represents the demand side of the economy as an optimizing $I S$-type of relationship where current output depends positively on its expected future value and negatively on the lagged real interest rate, $i_{t-1}-E_{t-1}\left[\pi_{t}\right]$. The presence of future output in the $I S$ intends to 
capture the effect of expected income on current spending and is theoretically justified by McCallum and Nelson (1999), among others, in the context of an optimizing general equilibrium model $^{5}$.

Aggregate demand depends positively on the past level of asset prices via consumption wealth effects and investment balance sheet effects. For example, a persistent decrease in the level of stock prices increases the perceived level of households' financial distress causing a reduction in consumption spending. The balance sheet channel implies a positive relationship between the firms' ability to borrow and their net worth which in turn depends on asset valuations. There is a vast amount of empirical evidence indicating that stock and house price movements are strongly correlated with aggregate demand in most major economies ${ }^{6}$. In our model, the central bank takes into account the effect of wealth on aggregate demand, that is, it is fully aware of the effect of $q_{t-1}$ on $y_{t}$ and its magnitude.

Eq. (2) depicts the price adjustment relation taking the form of a hybrid Phillips curve where current inflation is positively affected by its past and expected future value as well as the output gap. Hybrid Phillips curves have been developed in the literature in an effort to reduce the inconsistencies between purely forward-looking models and actual inflation data (see e.g. Clarida, Galí and Gertler, 1999).

Eqs. (3) and (4) represent the dynamic evolution of asset prices and their underlying fundamentals, respectively. We assume a partial adjustment mechanism of actual asset prices towards their fundamental value that allows for the appearance of a bubble buildup. As Eq. (3) indicates, if asset prices have increased in the past $\left(\Delta q_{t-1}>0\right)$ there is a positive 'momentum' effect on their current level $\left(b_{1}>0\right)$. The higher the value of $b_{1}$ the stronger the effect from past capital gains/losses and therefore $q_{t}$ can diverge significantly from its fundamental value, $q_{t}{ }^{*}$, albeit not permanently ${ }^{7}$. But once asset prices revert, at an unknown future date, the downward effect on aggregate demand could be large. We allow for reversion to fundamentals since if there is an decrease in the fundamentals $\left(q_{t}{ }^{*}<q_{t-1}\right)$ there is a negative pressure on $q_{t}$. The higher is $b_{2}$, the closer will be the co-movement between observed prices and the underlying fundamentals.

\footnotetext{
5 The expectational aggregate demand equation can be derived from the first order Euler condition for the representative household's optimal consumption choice problem assuming constant relative risk aversion and separability between consumption and leisure.

${ }^{6}$ See among others, Kontonikas and Montagnoli (2003) for relevant empirical evidence considering the UK economy.

${ }^{7} \mathrm{We}$ do not regard the divergence of $q_{t}$ from $q_{t}{ }^{*}$ as an explicit bubble because we do not assign any probabilistic structure to its evolution.
} 
Eq. (4) describes fundamental asset prices in line with the standard dividend model of asset pricing. There is a positive effect from expected future dividends (assumed to depend on expected output) and a negative effect from real interest rates. This is supported by the majority of empirical studies examining the effect of macroeconomic variables on the stock market ${ }^{8}$. We also allow for uncertainty in the fundamentals' process by including the random disturbance term, $u_{t}$.

In order to complete the model we need another equation describing the behaviour of the central bank. We will consider two types of rules for the period-by-period setting of the monetary policy instrument, $i_{t}$. Eq. (5) depicts a monetary policy rule that conditions the interest rate on concurrent inflation deviations from the target, the output gap ${ }^{9}$, as well as on asset price misalignments, $q_{t}-q_{t}^{*}$. If there is no response to asset price misalignments, $\gamma_{3}=0$, then Eq. (5) reduces to the standard Taylor rule (Taylor, 1993). In addition, we examine the case of an augmented inflation-forecast targeting rule, as given by Eq. (5'). In pure inflation-forecast based rules, $\gamma_{2}=\gamma_{3}=0$, and the only feedback variable for monetary policy is the deviation of inflation forecast from the target, $E_{t}\left[\pi_{t+j}\right]-\pi^{*}{ }^{10}$. In this case, the authorities' policy choice variables are the parameter triplet $\left\{\gamma_{1}^{*}, \gamma_{4}, j\right\}$. Parameter $\gamma_{1}^{*}$ has to be greater than one to satisfy the stability condition that real rates increase in response to expected inflation, with higher values implying a more aggressive response ${ }^{11}$. Parameters $\gamma_{4}$ and $j$ indicate the degree of interest rate smoothing by the central bank, and the horizon of the inflation forecast.

The system of Eqs. (1)-(5) can be expressed compactly as: $A E_{t}\left[X_{t+1}\right]=B X_{t}+C Z_{t}$

where the $(13 \times 1)$ endogenous variables vector

\footnotetext{
${ }^{8}$ See among others Fama (1981), Conover Jensen and Johnson (1999).

${ }^{9}$ We should point out that McCallum and Nelson (1999), and Orphanides et al (2000) among others, question the usual presumption that policymakers can actually observe $\tilde{y}_{t}$ when setting $i_{t}$. In an effort to enhance realism in the model, we replaced $\tilde{y}_{t}$ with $E_{t-1}\left[\tilde{y}_{t}\right]$ in the Taylor rule. The effect of this change on the simulation results, however, was quite small, as in McCallum (2001). The results are not presented here, but are available upon request from the authors.

${ }^{10}$ In some inflation targeting countries, e.g. United Kingdom, Sweden, Finland, actual monetary policy is linked to explicit (and often published) inflation forecasts. In other targeting countries though, e.g. Australia, inflation forecasts are less explicitly used in policy formulation. See Batini and Haldane (1999) for simulation evidence using forward-looking rules in a calibrated model of the UK economy.

${ }^{11}$ Similarly, $\gamma_{1}$ has to be greater than zero in Eq. (5) to ensure inflation stabilisation in the Taylor rule.
} 


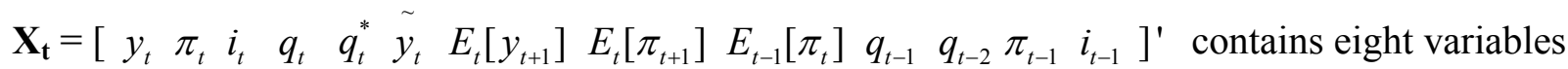
non-predetermined at time $t$, and five predetermined variables (4 lags of endogenous variables and one backward looking expectation). $\mathbf{Z}_{\mathbf{t}}$ is a $(6 \times 1)$ vector of exogenous variables containing the four stipulated random processes $\left(\eta_{t}, \varepsilon_{t}, \theta_{t}, u_{t}\right)$ plus the trend output, $\bar{y}_{t}$, and a constant ${ }^{12}$. A, B and C represent (13x13), (13x13) and (13x6) matrices of coefficients, respectively.

\section{Calibrating the model}

Prior to using stochastic simulations, we need to calibrate the model's behavioural parameters and perform impulse response analysis to ensure the plausibility of the chosen system. For the majority of the coefficients, the baseline values presented in Table 1 correspond to previous econometric evidence for the United Kingdom, over the inflation targeting period 19922002, by Kontonikas and Montagnoli (2003). Where econometric evidence is not available, the parameters are calibrated to ensure plausible dynamic behaviour by the impulse responses.

[Table 1 about here]

In the aggregate demand Eq. (1), the interest rate slope, $\alpha_{1}$, is set to 0.4 while the elasticity of output with respect to the past level of asset prices, $\alpha_{2}$, is 0.1 . In Eq. (2), we assume a strong effect from the backward-looking component of inflation by setting $\varphi=0.8$, while the slope of the Phillips curve, $\beta$, is 0.1 . The asset price adjustment Eq. (3) allows both for 'momentum trading' and 'fundamentals pull' since $b_{1}, b_{2} \neq 0$, with the former effect being rather stronger (0.5, as opposed to 0.3). In Eq. (4), the expected output effect on current fundamentals, $\delta_{2}$, is assumed to be twice as large as the interest rate effect, $\delta_{1},(0.8$ as opposed to 0.4$)$.

The baseline monetary policy rule parameters in Eqs. (5) and (5') posit a strong response to inflation, expected inflation ${ }^{13}\left(\gamma_{1}=0.8, \gamma_{1}{ }^{*}=3\right)$, a mild response to output and asset price misalignments $\left(\gamma_{2}=\gamma_{3}=0.1\right)$, and a high level of interest rate persistence $\left(\gamma_{4}=0.85\right)$. The long

\footnotetext{
${ }^{12}$ See Appendix for more technical details.

${ }^{13}$ In the inflation-forecast targeting rule we employ $j=2$, that is we allow for 2 year ahead forecast horizon. This is weakly consistent with actual behaviour by the Bank of England, since as Batini and Haldane (1999, p.9) point out, "...j defines the feedback horizon under the rule, whereas in practice in the United Kingdom, two years refers to the policy horizon (the point at which expected inflation and the inflation target are in line)."
} 
run real interest rate, $r$, is $3.5 \%$, and the inflation target, $\pi^{*}$ is set to $2.5 \%{ }^{14}$. Finally, the autoregressive coefficient of trend output is set to 0.95 , implying high persistence, and the standard deviations of the random shocks: $\sigma_{\eta}, \sigma_{\theta}, \sigma_{\varepsilon}, \sigma_{u}, \sigma_{\omega}$ are $0.015,0.003,0.002,0.1,0.006$ respectively (see also McCallum, 2001). This configuration of standard deviations allows asset price volatility to exceed output volatility by a factor of about 7 , and inflation volatility by a factor of 50. Hence, the asset price, via the influence of the shocks to fundamentals, $u_{t}$, is assumed to be the most volatile variable, in line with actual financial market behaviour, while inflation is the least volatile variable, capturing the price stability environment in which most central banks operate nowadays.

\subsection{Impulse response functions}

The results from the theoretical impulse response functions are presented in Figures $1-4^{15}$. Figure 1 plots the responses of output, inflation, interest rate, asset prices to a monetary policy shock. Following an increase in interest rates, inflation, output and asset prices decrease, a result consistent with a number of VAR studies (see e.g. Thorbecke, 1997). Figure 2 shows the impulse responses after a negative supply shock. Output and asset prices decline, while inflation and interest rates increase. In the case of positive demand shock (Figure 3), the initial response of all four variables is positive. Finally, as Figure 4 indicates, a positive shock in fundamentals leads to higher inflation and tighter monetary policy, while the initial impact on output and asset prices is positive. In summary, the economic system that we employ appears to be well specified, since we establish the presence of a monetary policy transmission mechanism that runs from interest rates to output, inflation and asset prices, without 'price-puzzle' in the inflation response, and negative effect from inflation to asset prices ${ }^{16}$.

[Figures 1-4 about here]

\subsection{Alternative policy choices}

We now turn our attention to the focal point of our analysis, that is, what are the welfare gains (or losses) when monetary policy chooses to react to asset price misalignments from the fundamentals. In the context of our model since there are wealth effects in aggregate demand, monetary policy already takes into account asset prices indirectly (and with lag) by responding to

\footnotetext{
${ }^{14}$ The average nominal interest rate in the United Kingdom over the inflation targeting period 1992:10-2002:01 was about $6 \%$.

${ }^{15}$ Figures 1-4 plot the impulse responses for the asset price-augmented Taylor rule case. Similar patterned results, available from the authors upon request, were obtained using inflation-forecast targeting monetary policy rule.

${ }^{16}$ See among others, Canova and De Nicolo (1997) for relevant empirical evidence.
} 
output movements. The question that then arises is whether an extra direct reaction to deviations from fundamentals is stabilizing the economic system or not.

Bernanke and Gertler's $(1999,2001)$ simulation evidence suggests that an aggressive inflation-forecast targeting rule $\left(\gamma_{1}^{*}=3\right)$ clearly dominates both 'accommodative' rules $\left(\gamma_{1}^{*}=1.01\right)$, and rules that have been augmented by a variable expressing the level of asset prices. They also show that, in agreement with the view that inflation targeting should be applied 'flexibly', policy should also respond to the output gap as well $\left(\gamma_{2}>0\right)$. Thus, monetary policy should respond to movements in asset prices only insofar as they affect the inflation forecast. Cecchetti, Genberg, Lipsky and Wadhwani (2000) reach strikingly different conclusions using the same model as Bernanke and Gertler (1999). They suggest that the central bank can reduce inflation and output volatility by adjusting interest rates in response to asset price misalignments even when inflation remains on track. The differences in their results can be attributed to the simulation procedures employed ${ }^{17}$.

Representative simulation results using the Taylor rule and inflation forecast-targeting rule are shown in Tables 2-3, respectively. The first column of Tables 1-2 presents the response of the nominal interest rate to asset price misalignments, $q_{t}-q_{t}^{*}$. The second to fourth column show the unconditional variances (in percentage points) of output, $\sigma_{y}$, inflation, $\sigma_{\pi}$, interest rates, $\sigma_{i}$, and asset prices, $\sigma_{q}$. In the absence of discounting, quadratic losses for alternative policy rules can be calculated as linear combinations of the unconditional variances of these variables:

$$
L=a \sigma_{\pi}+b \sigma_{y}+c \sigma_{i}+d \sigma_{q}
$$

where $(\alpha, b, c, d)$ denote the respective weights that the central bank attaches on inflation, output, interest rate and asset price volatility ${ }^{18}$.

We consider four alternative sets of weights: $(\alpha, b, c, d)=(1,0.5,0.3,0),(1,0.5,0.3,0.1),(1,1,0.3,0),(1,1,0.3,0.1)$, via which we obtain the alternative loss functions $L_{1}, L_{2}, L_{3}$ and $L_{4}$ respectively. $L_{1}$ and $L_{3}$ put zero weight on asset price volatility, while $L_{2}$ and $L_{4}$ penalise asset price volatility with a factor of $0.1 . L_{3}$ and $L_{4}$

\footnotetext{
${ }^{17}$ As Bernanke and Gertler (2001) point out, Cecchetti et al (2000) allow only bubble-type shocks to drive asset prices and do not take into account the probabilistic structure of the stock market bubble.

${ }^{18}$ We should point out that as McCallum (2001) argues, no actual central bank has yet publicly disclosed an explicit objective/loss function and the weights given to each variable. Hence, in analysing the effects of monetary policy
} 
correspond to the case of equal weight on inflation and output volatility, while $L_{1}$ and $L_{2}$ recognise price stability as the primary objective of monetary policy, as the weight on inflation volatility is double the weight on output volatility. Penalising inflation and output volatility reflects a wide agreement that they represent important concerns for monetary policymakers ${ }^{19}$. Inclusion of asset price volatility in $L_{2}$ and $L_{4}$ stems from the arguments put forth in Borio and Lowe (2002), where it is acknowledged that apart from monetary stability (defined mainly as price stability), financial stability is also crucial and should be taken into account explicitly by policymakers, since price stability doesn't necessarily guarantee or promote financial stability. All the above specifications penalise instrument (interest rate) volatility with a factor of $0.3^{20}$.

[Tables 2, 3 about here]

The results in Tables 2, 3 indicate a mild response to asset price misalignments, i.e. $\gamma_{3}=0.1$, is successful in reducing overall macroeconomic volatility using all the alternative loss functions and monetary policy rules under investigation. Using both the Taylor rule and the inflation-forecast targeting rule, we notice that if the monetary authority reacts too strongly to asset prices $\left(\gamma_{3}>0.1\right)$, aggregate welfare losses, as indicated by all the loss functions, increase due to the higher inflation, output and interest rate volatility, despite the decrease in asset price volatility (in the case of $L_{1}$ and $L_{4}$ ). Our results differ from the findings of Bernanke and Gertler (2001) since, as we show in Table 3, there is an incentive for the central bank to take into account asset prices even conditional to a strong response to expected inflation, as the inflation-forecast targeting suggests. The differences may derive, among other factors, from the fact that in our policy rules we consider asset price deviations from fundamentals, instead of the price of capital (Tobin's $q$ ) as in Bernanke and Gertler.

The reduction in welfare losses that we obtain with our preferred rule $\left(\gamma_{3}=0.1\right)$ derives from the lower asset price and output volatility, as compared to the baseline rule $\left(\gamma_{3}=0\right)$. The increased inflation and interest rate variability has been more than compensated from the sharp decreases in output and asset price volatility. For example, in the inflation-forecast targeting case, $\sigma_{y}$ declines from 1.93 to 1.70 , and $\sigma_{q}$ from 10.81 to 10.59 .

rules on macroeconomic volatility, McCallum opts for the evaluation of alternative rules that are not necessarily derived from optimisation subject to a loss/objective function of the monetary authority.

${ }^{19}$ See for instance the discussion in Rudebusch and Svensson (1999). 
[Tables 4, 5 about here]

In Tables 4,5 we evaluate the behaviour of the economic system by varying simultaneously the parameter responding to inflation $\left(\gamma_{1}, \gamma_{1}^{*}\right)$ and the parameter associated with asset price misalignments $\left(\gamma_{3}\right)$. Specifically, we are postulating two regimes regarding the response of interest rates to inflation: an accommodating regime $\left(\gamma_{1}=0.05, \gamma_{1}^{*}=1.05\right)$, and an aggressive regime $\left(\gamma_{1}=2, \gamma_{1}^{*}=3\right)$, while with each of the regimes we allow two different values of the parameter associated with asset price misalignments: $\gamma_{3}=0$, and $\gamma_{3}=0.1$. In addition, we allow for three instances where the parameter associated with the output gap, $\gamma_{2}$, assumes a value of 0.5. This value was chosen because it was advocated by Taylor (1993) as the appropriate response of the central bank to the output gap, independently of its attitude towards inflation. The simulation evidence reveals the existence of inflation-output volatility frontiers, since when $\gamma_{2}$ increases from 0 to 0.5 , output volatility declines and inflation volatility increases, for any given $\gamma_{1}$. For instance, in the case of the accommodative rule (first \& second row of Table 4) with $\gamma_{3}=0.1, \sigma_{y}$ declines from 2.42 to 2.03 , while $\sigma_{\pi}$ increases from 1.64 to 2.36.

When, however, the monetary authority becomes more averse with respect to inflation, not only inflation but also output volatility declines in agreement with previous work of McCallum (2001). For example, switching from $\left(\gamma_{1}, \gamma_{2}, \gamma_{3}\right)=(0.05,0,0)$, to $(2,0,0)$ reduces $\sigma_{\pi}$ by $50 \%$ and $\sigma_{y}$ by about $20 \%$. Considering the reaction to asset prices, we find that when monetary policy responds to misalignments, asset market and output volatility always decline leading to lower $L$ 's, conditional upon non-inflation accommodation, i.e. $\gamma_{1}>0.05$. The smallest realisations of the alternative loss functions occur at $\left(\gamma_{1}, \gamma_{2}, \gamma_{3}\right)=(2,0.5,0.1)$.

Assuming for simplicity that $r=\pi^{*}=0$, and no interest rate persistence in Eq. (5), the rule for operating nominal short term interest rate target, $i_{t}{ }^{*}$, that appears to lead to minimum losses is: $i_{t}^{*}=3 \pi_{t}+0.5 \tilde{y_{t}}+0.1\left(q_{t}-q_{t}^{*}\right)$

where, the differences from the traditional Taylor rule are a much stronger response (twice as large) to inflation and an additional mild response to the asset variable.

\footnotetext{
${ }^{20}$ Woodford (1999) provides an incentive for considering instrument volatility by stressing that more variable interest rates may undermine the central bank's credibility.
} 
As we see in Table 5, using the inflation-forecast based rule, there are welfare gains from monetary policy reaction to misalignments only when ${\gamma_{1}}^{*}>1.05$, that is, aggressive inflationforecast targeting. The stronger the reaction to expected inflation the greater the reduction in macroeconomic volatility. Comparing the last row of Tables 4 and 5 respectively, that correspond to the inflation-averse case, we notice that the Taylor rule that includes both asset price misalignments and the output gap leads to lower aggregate volatility as compared to the augmented (by asset price misalignments) inflation-forecast rule. Hence, we agree with Bernanke and Gertler (2001) that inflation targeting should be 'flexible' with an independent role for the output gap.

\section{Conclusions}

This paper examines the relationship between monetary policy and asset prices using a structural model of the economy that allows for the effect of asset prices on aggregate demand. The sharp reduction in stock prices on early 2000, and the continuing worldwide increases in house prices have resulted in growing interest among academics and policymakers to study the links between monetary policy, asset market developments and the real economy. Financial imbalances and the economic instability associated with pronounced asset price misalignments pose important challenges for monetary policymakers. Concentrating on price stability alone, as a growing number of inflation targeting countries do, is no guarantee that financial instability and the serious after-effects of bubbles bursting can be avoided. Taking these arguments into consideration, we start from a small scale rational expectations macro model where, in line with recent empirical findings and theoretical intuition, the current level of output is positively related to lagged real asset prices. In this study, we contribute to the existing literature by employing an alternative model for the dynamic evolution of asset prices. We assume that asset prices follow a partial adjustment mechanism in the context of which, they are positively affected by past changes, while at the same time we also allow for reversion towards their fundamental value.

Analyzing whether the central bank should take into account asset price misalignments when setting interest rates, we consider both the inflation-forecast targeting rule and the standard Taylor rule. The main result of our simulations is that a mild response to asset price deviations from fundamentals promotes overall macroeconomic stability. This result is robust to all four postulated loss functions and policy rules. Monetary policy should not only react strongly to inflation (or its forecast) but should also take into account output developments and asset price 
misalignments. We acknowledge that it may be difficult to interpret asset price movements and distinguish between fundamental and non-fundamental components, but the same type of uncertainty exists when policy makers are faced with stochastic trend output. Hence, there is scope for the monetary authorities to take into account asset price misalignments in the conduct of monetary policy despite the measurement errors that they might face. 


\section{References}

Batini, N., and Haldane, G. (1999). "Forward-looking Rules for Monetary Policy", Bank of England Working Paper, No. 91.

Bernanke, B., and Gertler, M. (2001). "Should Central Banks Respond to Movements in Asset Prices?”, American Economic Review Papers and Proceedings, Vol. 91, pp. 253-257.

Bernanke, B., and Gertler, M. (1999). "Monetary Policy and Asset Price Volatility", Economic Review, Federal Reserve of Kansas City, Fourth Quarter, pp. 17-51.

Borio, C., and Lowe, P. (2002). "Asset prices, Financial and Monetary Stability: Exploring the Nexus", BIS Working Paper, No. 114.

Bordo, M., and Jeanne, O. (2002). "Boom-Busts in Asset Prices, Economic Instability, and Monetary Policy", NBER Working Paper, No. 8966.

Canova, F., and De Nicolo, G. (1997). "Stock Returns, Term Structure, Inflation and Real Activity: An International Perspective", CEPR Discussion Paper, No. 1614.

Cecchetti, S., Genberg, H., Lipsky, J., and Wadhwani, S. (2000). Asset Prices and Central Bank Policy, International Centre for Monetary and Banking Studies, London.

Conover M., Jensen, G.R., and Johnson, R.R.(1999). "Monetary Environments and International Stock Returns", Journal of Banking and Finance, Vol. 23, pp. 1357-1381.

Clarida, R., Galì, J., and Gertler, M. (1999). "The Science of Monetary Policy: A New Keynesian Perspective”, Journal of Economic Literature, Vol. 37, pp. 1661-1707.

Detken, K., and Smets, F. (2003). "Asset Price Booms and Monetary Policy", mimeo.

Fama, E. (1981). "Stock Returns, Real Activity, Inflation and Money", American Economic Review, Vol. 71, pp. 545-565.

Garber, P., (2000). Famous First Bubbles: The Fundamentals of Early Manias, Cambridge, MIT Press.

Gilchrist, S., and Leahy, J. (2002). "Monetary Policy and Asset Prices", Journal of Monetary Economics, Vol. 49, pp. 75-97.

Goodhart, C., and Hofmann, B. (2000). "Financial Variables and the Conduct of Monetary Policy", Sveriges Riskbank Working Paper, No. 12.

Goodhart, C., and Hofmann, B. (2001). "Asset Prices, Financial Conditions, and the Transmission of Monetary Policy", paper presented at the conference on 'Asset Prices, Exchange Rate, and Monetary Policy', Stanford University, March.

Goodhart, C., and Hofmann, B. (2003). "Deflation, Credit and Asset Prices", Hong Kong Institute for Monetary Research Working Paper, No. 13/2003.

IMF, (2003). "When Bubbles Burst". World Economic Outlook, Chapter 2, April, pp. 61-94.

Klein, P. (2000). "Using the Generalized Schur Form to Solve a Multivariate Linear Rational Expectations Model”, Journal of Economic Dynamics and Control, Vol. 24, pp. 1405-1423.

Kontonikas, A., and Montagnoli, A. (2003). "Has Monetary Policy Reacted to Asset Price Movements? Evidence from the United Kingdom”, Ekonomia, forthcoming.

Kocherlakota, N. (2000). "Creating Business Cycles Through Credit Constraints", Federal Reserve Bank of Mineapolis Quartely Review, Vol. 24, pp. 2-10.

McCallum, B. (1998). "Solutions to Linear Rational Expectations Models: A Compact Exposition”, Economic Letters, Vol. 61, pp. 143-147.

McCallum, B., and Nelson, E. (1999). "An Optimizing IS-LM specification for Monetary Policy and Business Cycle Analysis", Journal of Money Credit and Banking, Vol. 31, pp. 296-316. McCallum, B. (2001). "Should Monetary Policy Respond Strongly to Output Gaps?", American Economic Review Papers and Proceedings, Vol. 91, pp. 258-262. 
Orphanides, A., Porter, R., Reifschneider, D., Tetlow, R., and Finan, F. (2000). "Errors in the measurement of the output gap and the design of monetary policy," Journal of Economics and Business, Vol. 52, pp. 117-141.

Rudebusch, G., and Svensson, L. (1999). "Policy Rules for Inflation Targeting", in John B. Taylor (ed.), Monetary Policy Rules, University Chicago Press.

Taylor, J.B. (1993). "Discretion Versus Policy Rules in Practice", Carnegie-Rochester Conference Series on Public Policy, Vol. 39, pp.195-214.

Thorbecke, W. (1997). "On Stock Market Returns and Monetary Policy”, Journal of Finance, Vol. 52, pp. 635-654.

Vile, A. (2000). "Asset Price Crises and Banking Crises: Some Empirical Evidence", BIS Conference Paper Series on: International financial markets and the implications for monetary and financial stability.

Woodford, M. (1999). “Optimal Monetary Policy Inertia”, NBER Working Paper, No. 7261. 


\section{APPENDIX}

Using the fact that the asset price Eq. 3 can be re-written as:

$q_{t}=\left(b_{1}-b_{2}\right) q_{t-1}-b_{1} q_{t-2}+b_{2} q_{t}^{*}$

Equations (1-5) can be compactly expressed as:

$A E_{t}\left[X_{t+1}\right]=B X_{t}+C Z_{t}$

where

$\mathbf{X}_{\mathbf{t}}=\left[\begin{array}{l}y_{t} \\ \pi_{t} \\ i_{t} \\ q_{t} \\ q_{t}^{*} \\ \tilde{y}_{t} \\ E_{t}\left[y_{t+1}\right] \\ E_{t}\left[\pi_{t+1}\right] \\ E_{t-1}\left[\pi_{t}\right] \\ q_{t-1} \\ q_{t-2} \\ \pi_{t-1} \\ i_{t-1}\end{array}\right] \quad E_{t}\left[\mathbf{X}_{t+1}\right]=\left[\begin{array}{l}E_{t}\left[y_{t+1}\right] \\ E_{t}\left[\pi_{t+1}\right] \\ E_{t}\left[i_{t+1}\right] \\ E_{t}\left[q_{t+1}\right] \\ E_{t}\left[q_{t+1}^{*}\right] \\ E_{t}\left[\tilde{y}_{t+1}\right] \\ E_{t}\left[y_{t+2}\right] \\ E_{t}\left[\pi_{t+2}\right] \\ E_{t}\left[\pi_{t+1}\right] \\ q_{t} \\ q_{t-1} \\ \pi_{t} \\ i_{t}\end{array}\right]$

$\mathbf{Z}_{\mathbf{t}}=\left[\begin{array}{c}\eta_{t} \\ \varepsilon_{t} \\ \theta_{t} \\ u_{t} \\ \overline{y_{t}} \\ 1\end{array}\right]$ 


$$
\mathbf{A}=\left[\begin{array}{lllllllllllll}
1 & 0 & 0 & 0 & 0 & 0 & 0 & 0 & 0 & 0 & 0 & 0 & 0 \\
0 & 1 & 0 & 0 & 0 & 0 & 0 & 0 & 0 & 0 & 0 & 0 & 0 \\
0 & 0 & 0 & 0 & 0 & 0 & 0 & 0 & 0 & 1 & 0 & 0 & 0 \\
0 & 0 & 0 & 0 & 0 & 0 & 0 & 0 & 0 & 0 & 0 & 1 & 0 \\
0 & 0 & 0 & 0 & 0 & 0 & 0 & 0 & 0 & 0 & 0 & 0 & 1 \\
0 & 0 & 0 & 0 & 0 & 0 & 0 & 0 & 0 & 0 & 0 & 0 & 0 \\
0 & 0 & 0 & 0 & 0 & 0 & 0 & 0 & 0 & 0 & 1 & 0 & 0 \\
0 & 0 & 0 & 0 & 0 & 0 & 0 & 0 & 0 & 0 & 0 & 0 & 0 \\
0 & 0 & 0 & 0 & 0 & 0 & 0 & 0 & 0 & 0 & 0 & 1 & 0 \\
0 & 0 & 0 & 0 & 0 & 0 & 0 & 0 & 0 & 0 & 0 & 0 & 1 \\
0 & 0 & 0 & 0 & 0 & 0 & 0 & 0 & 0 & 0 & 0 & 0 & 0 \\
0 & 0 & 0 & 0 & 0 & 0 & 0 & 0 & 0 & 1 & 0 & 0 & 0
\end{array}\right]
$$

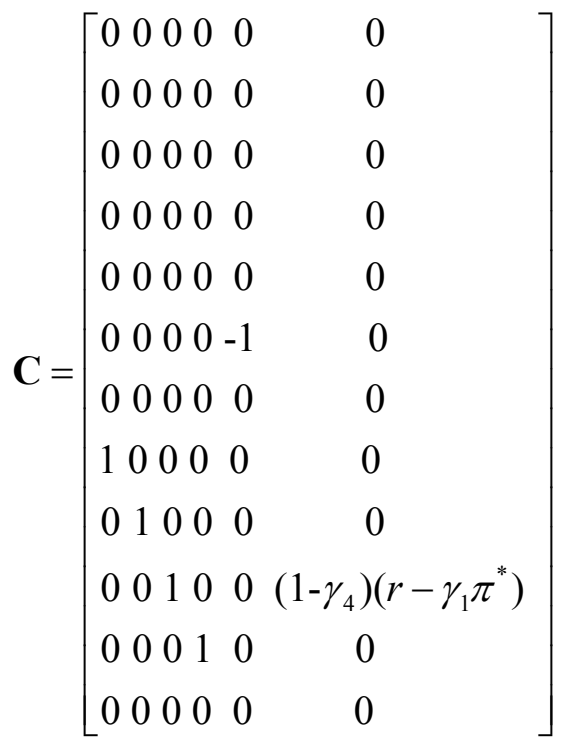

$$
\mathbf{B}=\left[\begin{array}{ccccccccccccc}
0 & 0 & 0 & 0 & 0 & 0 & 1 & 0 & 0 & 0 & 0 & 0 & 0 \\
0 & 0 & 0 & 0 & 0 & 0 & 0 & 1 & 0 & 0 & 0 & 0 & 0 \\
0 & 0 & 0 & 1 & 0 & 0 & 0 & 0 & 0 & 0 & 0 & 0 & 0 \\
0 & 1 & 0 & 0 & 0 & 0 & 0 & 0 & 0 & 0 & 0 & 0 & 0 \\
0 & 0 & 1 & 0 & 0 & 0 & 0 & 0 & 0 & 0 & 0 & 0 & 0 \\
1 & 0 & 0 & 0 & 0 & -1 & 0 & 0 & 0 & 0 & 0 & 0 & 0 \\
0 & 0 & 0 & 0 & 0 & 0 & 0 & 0 & 0 & 1 & 0 & 0 & 0 \\
-1 & 0 & 0 & 0 & 0 & 0 & 1 & 0 & \alpha_{1} & \alpha & 0 & 0 & -\alpha_{1} \\
0 & 0 & 0 & 0 & 0 & \beta & 0 & (1-\varphi) & 0 & 0 & 0 & \varphi & 0 \\
0 & \left(1-\gamma_{4}\right)\left(1+\gamma_{1}\right) & 0 & \left(1-\gamma_{4}\right) \gamma_{3} & -\left(1-\gamma_{4}\right) \gamma_{3} & \left(1-\gamma_{4}\right) \gamma_{2} & 0 & 0 & 0 & 0 & 0 & 0 & \gamma_{4} \\
0 & 0 & -\delta_{1} & 0 & -1 & 0 & \delta_{2} & \delta_{1} & 0 & 0 & 0 & 0 & 0 \\
0 & 0 & 0 & 0 & b_{2} & 0 & 0 & 0 & 0 & \left(b_{1}-b_{2}\right) & -b_{1} & 0 & 0
\end{array}\right]
$$

The above multivariate linear rational expectations (RE) model is solved in Matlab using the generalized Schur form. The core algorithm that we used to calculate numerical solutions is solvek.m, whose more detailed analysis may be found in McCallum (1998). It is a modified version of the Klein (2000) algorithm. 
Figure 1: Impulse responses to unit shock to the interest rate.
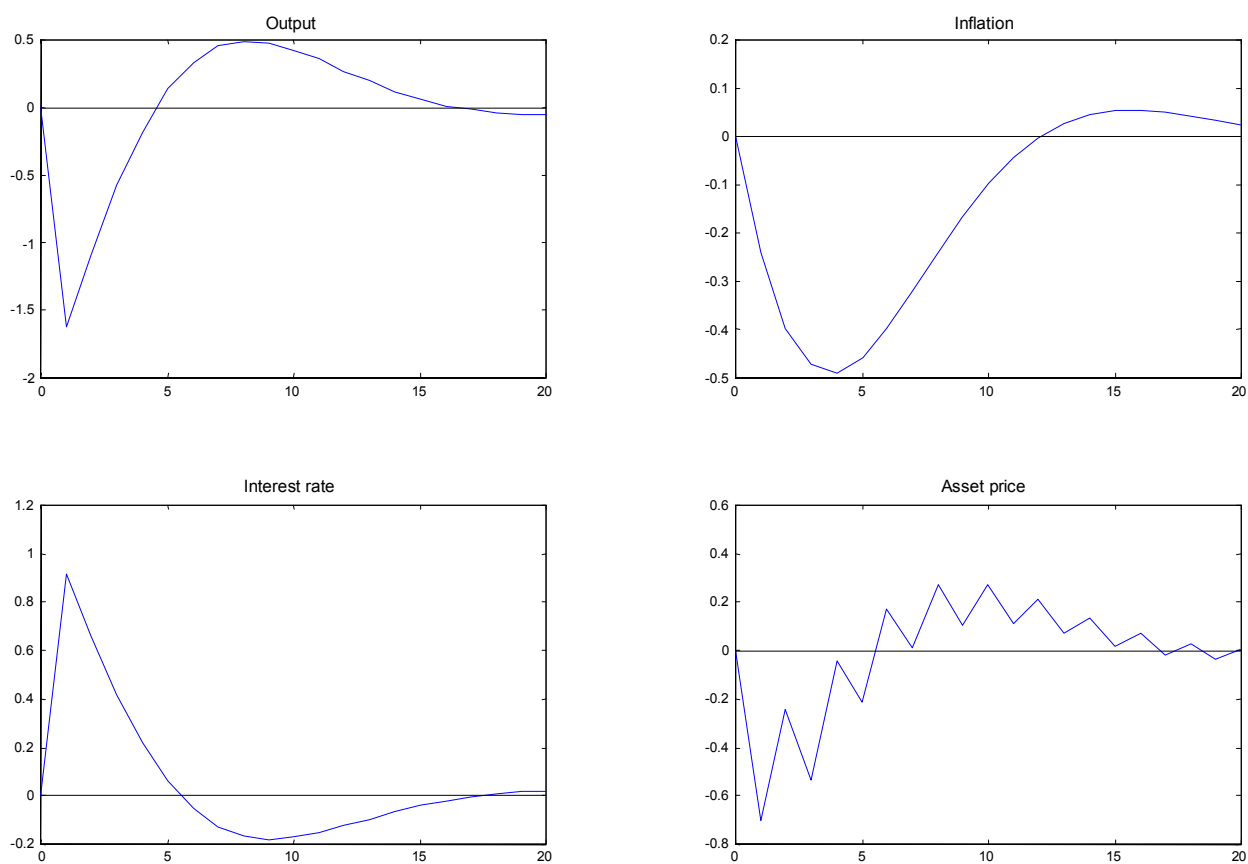

Figure 2: Impulse responses to unit shock to the inflation rate.
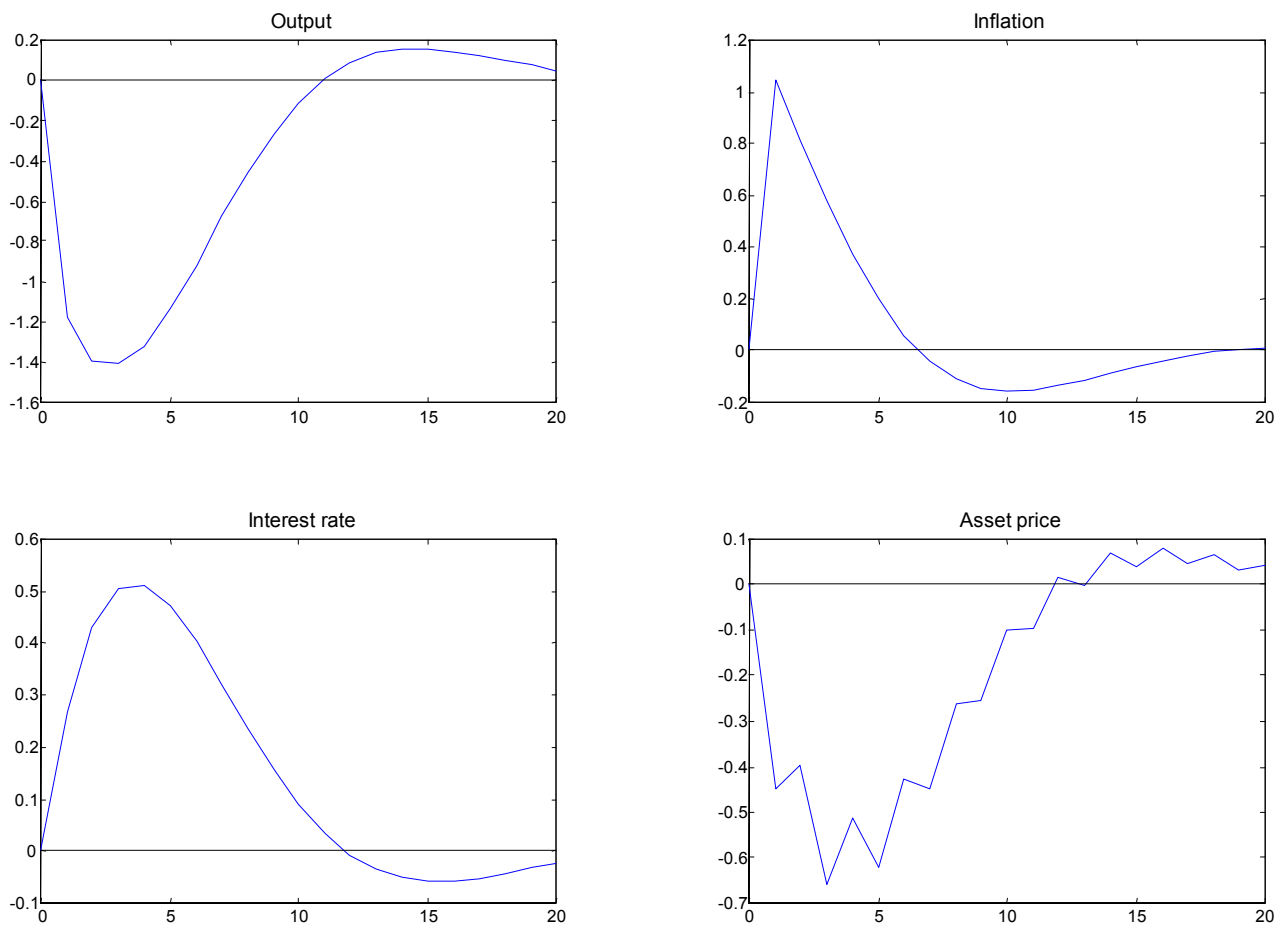
Figure 3: Impulse responses to unit shock to the aggregate demand.
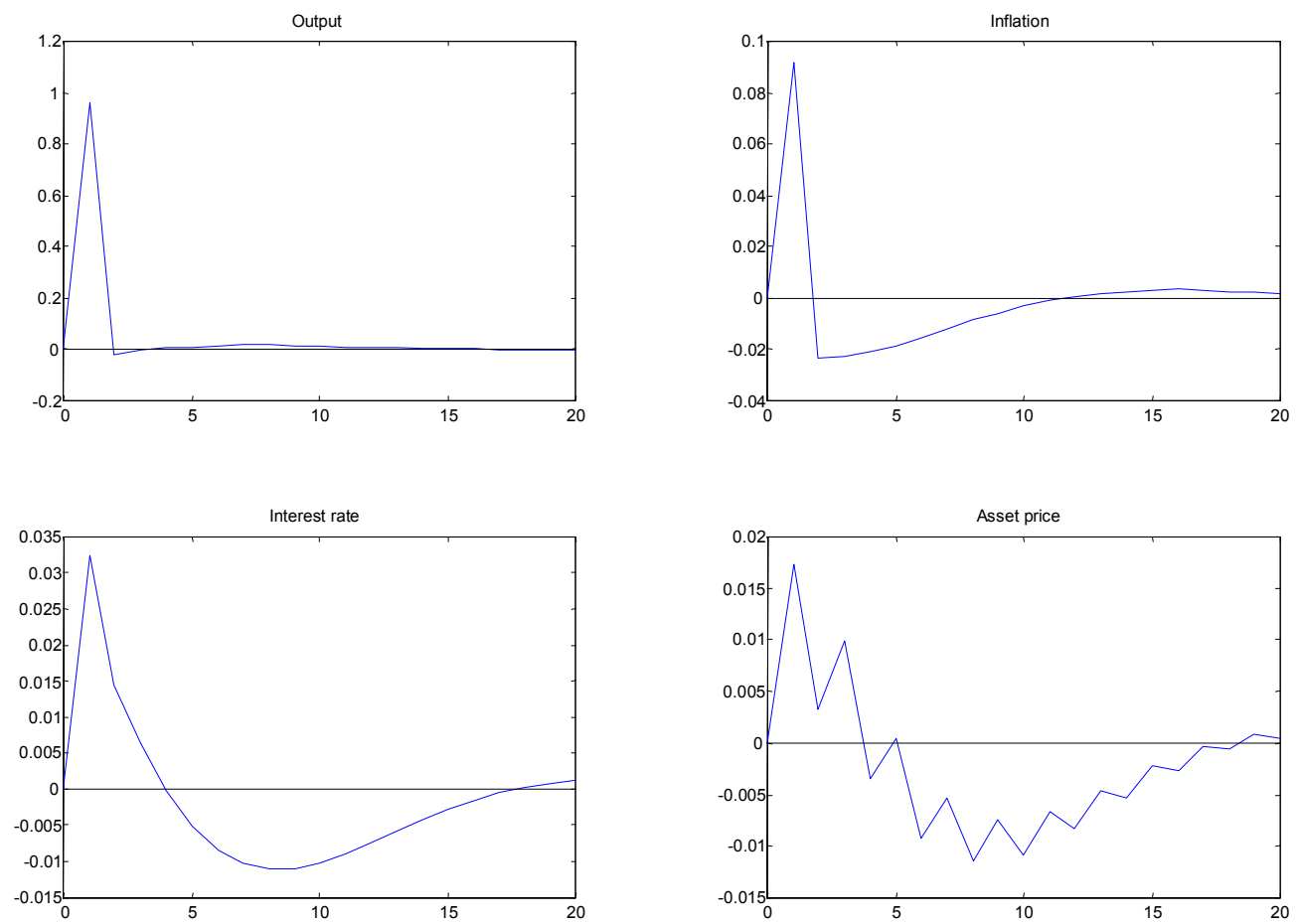

Figure 4: Impulse responses to unit shock to the fundamentals.
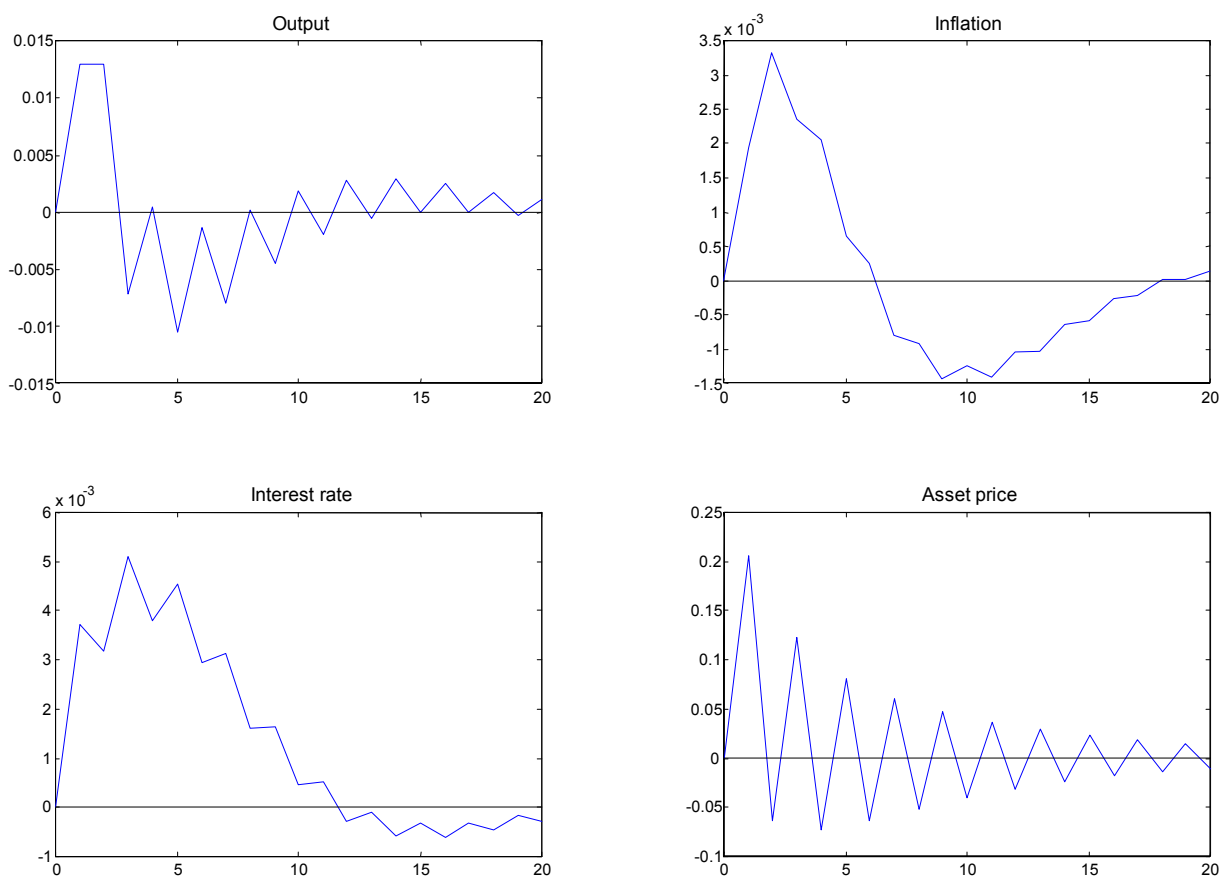
TABLES

Table 1: Model Calibration

\begin{tabular}{|c|c|c|c|}
\hline \multicolumn{5}{|c|}{ Parameter } \\
\hline$a_{1}$ & 0.4 & $\gamma_{1}$ & 0.8 \\
\hline$a_{2}$ & 0.1 & $\gamma_{1}^{*}$ & 3 \\
\hline$\varphi$ & 0.8 & $\gamma_{2}$ & 0.1 \\
\hline$\beta$ & 0.1 & $\gamma_{3}$ & 0.1 \\
\hline$\delta_{1}$ & 0.4 & $\gamma_{4}$ & 0.85 \\
\hline$\delta_{2}$ & 0.8 & $r$ & 0.035 \\
\hline$b_{1}$ & 0.5 & $\pi$ & 0.025 \\
\hline$b_{2}$ & 0.3 & & \\
\hline
\end{tabular}


Table 2: Standard deviations of output, inflation, interest rates, asset prices, using the Taylor rule

\begin{tabular}{|c|c|c|c|c|c|c|c|c|}
\hline$\gamma_{3}$ & $\sigma_{y}$ & $\sigma_{\pi}$ & $\sigma_{i}$ & $\sigma_{q}$ & $L_{1}$ & $L_{2}$ & $L_{3}$ & $L_{4}$ \\
\hline 0 & 2.13 & 0.89 & 0.84 & 11.06 & 2.21 & 3.31 & 3.27 & 4.38 \\
\hline 0.1 & 1.93 & 0.94 & 0.83 & 10.17 & 2.15 & 3.17 & 3.12 & 4.14 \\
\hline 0.5 & 1.95 & 1.45 & 1.31 & 8.60 & 2.79 & 3.65 & 3.73 & 4.59 \\
\hline 1 & 2.14 & 2.08 & 2.11 & 7.62 & 3.78 & 4.55 & 4.85 & 5.62 \\
\hline
\end{tabular}

Note:

(a) The standard deviations have been calculated using the baseline parameter values from Table 1 .

(b) $L_{1}, L_{2}, L_{3}, L_{4}$ denote the value of the Loss function, $L=a \sigma_{\pi}+b \sigma_{y}+c \sigma_{i}+d \sigma_{q}$, for $(a, b, c, d)=(1,0.5,0.3,0)$, $(1,0.5,0.3,0.1),(1,1,0.3,0),(1,1,0.3,0.1)$ respectively.

Table 3: Standard deviations of output, inflation, interest rates, asset prices, using the inflation-forecast targeting rule

\begin{tabular}{|c|c|c|c|c|c|c|c|c|}
\hline$\gamma_{3}$ & $\sigma_{y}$ & $\sigma_{\pi}$ & $\sigma_{i}$ & $\sigma_{q}$ & $L_{1}$ & $L_{2}$ & $L_{3}$ & $L_{4}$ \\
\hline 0 & 1.93 & 0.77 & 0.82 & 10.81 & 1.98 & 3.06 & 2.95 & 4.03 \\
\hline 0.1 & 1.70 & 0.84 & 0.88 & 10.59 & 1.95 & 3.01 & 2.80 & 3.86 \\
\hline 0.5 & 1.74 & 1.08 & 1.18 & 8.81 & 2.30 & 3.19 & 3.17 & 4.06 \\
\hline 1 & 1.95 & 1.39 & 1.75 & 7.90 & 2.89 & 3.68 & 3.87 & 4.66 \\
\hline
\end{tabular}

Note:

(a) The standard deviations have been calculated using the parameter values from Table 1.

(b) $L_{1}, L_{2}, L_{3}, L_{4}$ denote the value of the Loss function, $L=a \sigma_{\pi}+b \sigma_{y}+c \sigma_{i}+d \sigma_{q}$, for $(a, b, c, d)=(1,0.5,0.3,0)$, $(1,0.5,0.3,0.1),(1,1,0.3,0),(1,1,0.3,0.1)$ respectively. 
Table 4: Standard deviations of output, inflation, interest rates, asset prices, using the Taylor rule and alternative

values of $\left(\gamma_{1}, \gamma_{2}, \gamma_{3}\right)$

\begin{tabular}{|c|c|c|c|c|c|c|c|c|c|}
\hline$\left(\gamma_{1}, \gamma_{2}\right)$ & $\gamma_{3}$ & $\sigma_{y}$ & $\sigma_{\pi}$ & $\sigma_{i}$ & $\sigma_{q}$ & $L_{1}$ & $L_{2}$ & $L_{3}$ & $L_{4}$ \\
\hline \multirow{2}{*}{$(0.05,0)$} & 0 & 2.51 & 1.43 & 0.90 & 11.04 & 2.96 & 4.06 & 4.21 & 5.32 \\
& 0.1 & 2.42 & 1.64 & 0.96 & 10.33 & 3.14 & 4.17 & 4.35 & 5.38 \\
\hline \multirow{2}{*}{$(0.05,0.5)$} & 0 & 2.22 & 1.90 & 1.20 & 10.88 & 3.37 & 4.46 & 4.48 & 5.57 \\
& 0.1 & 2.03 & 2.36 & 1.68 & 10.20 & 3.88 & 4.90 & 4.89 & 5.91 \\
\hline \multirow{2}{*}{$(1,0)$} & 0 & 1.98 & 0.87 & 0.92 & 10.58 & 2.13 & 3.19 & 3.12 & 4.18 \\
& 0.1 & 1.82 & 0.92 & 0.93 & 10.08 & 2.11 & 3.11 & 3.02 & 4.03 \\
\hline \multirow{2}{*}{$(1,0.5)$} & 0 & 1.78 & 0.99 & 0.94 & 10.53 & 2.16 & 3.21 & 3.04 & 4.10 \\
& 0.1 & 1.68 & 1.03 & 0.93 & 10.05 & 2.14 & 3.15 & 2.98 & 3.99 \\
\hline \multirow{2}{*}{$(2,0)$} & 0 & 1.99 & 0.71 & 1.01 & 10.68 & 2.00 & 3.07 & 3.00 & 4.07 \\
& 0.1 & 1.89 & 0.73 & 0.97 & 10.28 & 1.97 & 2.99 & 2.92 & 3.95 \\
\hline \multirow{2}{*}{$(2,0.5)$} & 0 & 1.80 & 0.75 & 0.95 & 10.49 & 1.93 & 2.98 & 2.83 & 3.88 \\
& 0.1 & 1.67 & 0.80 & 0.94 & 10.22 & 1.92 & 2.95 & 2.76 & 3.79 \\
\hline
\end{tabular}

Note:

(a) The standard deviations have been calculated using the parameter values from Table 1.

(b) $L_{1}, L_{2}, L_{3}, L_{4}$ denote the value of the Loss function, $L=a \sigma_{\pi}+b \sigma_{y}+c \sigma_{i}+d \sigma_{q}$, for $(a, b, c, d)=(1,0.5,0.3,0)$, $(1,0.5,0.3,0.1),(1,1,0.3,0),(1,1,0.3,0.1)$ respectively. 
Table 5: Standard deviations of output, inflation, interest rate, asset prices using the inflation-forecast targeting rule and alternative values of $\left(\gamma_{1}^{*}, \gamma_{3}\right)$.

\begin{tabular}{|c|c|c|c|c|c|c|c|c|c|}
\hline$\gamma_{1}^{*}$ & $\gamma_{3}$ & $\sigma_{y}$ & $\sigma_{\pi}$ & $\sigma_{i}$ & $\sigma_{q}$ & $L_{1}$ & $L_{2}$ & $L_{3}$ & $L_{4}$ \\
\hline \multirow{2}{*}{1.05} & 0 & 2.66 & 1.51 & 0.80 & 11.47 & 3.08 & 4.23 & 4.41 & 5.55 \\
& 0.1 & 2.48 & 1.77 & 0.93 & 10.58 & 3.28 & 4.34 & 4.52 & 5.58 \\
\hline \multirow{2}{*}{2} & 0 & 2.06 & 0.93 & 0.82 & 10.93 & 2.20 & 3.29 & 3.23 & 4.32 \\
& 0.1 & 1.85 & 0.98 & 0.81 & 10.20 & 2.15 & 3.17 & 3.07 & 4.09 \\
\hline \multirow{2}{*}{3} & 0 & 1.96 & 0.77 & 0.83 & 10.88 & 2.00 & 3.09 & 2.98 & 4.07 \\
& 0.1 & 1.83 & 0.80 & 0.84 & 10.30 & 1.97 & 3.00 & 2.88 & 3.91 \\
\hline
\end{tabular}

Note:
(a) The standard deviations have been calculated using the parameter values from Table 1.
(b) $L_{1}, L_{2}, L_{3}, L_{4}$ denote the value of the Loss function, $L=a \sigma_{\pi}+b \sigma_{y}+c \sigma_{i}+d \sigma_{q}$, for $(a, b, c, d)=(1,0.5,0.3,0)$, $(1,0.5,0.3,0.1),(1,1,0.3,0),(1,1,0.3,0.1)$ respectively. 